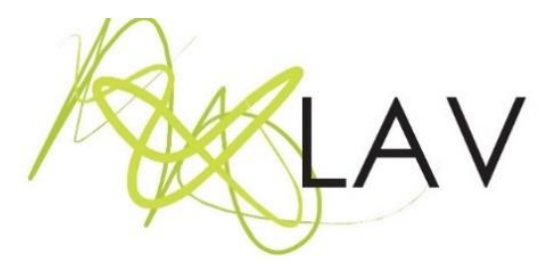

Dilatação corporal, performance art e a docência: um percurso de criação visual

Body expansion, performance art and teaching: a visual creation course

Leomar Peruzzoi

Universidade Regional De Blumenau

Carla Carvalhoii

Universidade Regional De Blumenau

Pedro Gottardiiii

Universidade Regional De Blumenau

\begin{abstract}
Resumo
Neste texto, um corpo de professor/artista/pesquisador coloca-se em processo de criação. Esse é nosso lugar de partida e, ao mesmo tempo que criamos, percorremos os conceitos reflexivos da pesquisa em arte e educação. Este estudo explora as potencialidades do corpo em um processo criativo que parte do conceito de dilatação corporal para desencadear a criação de visualidades. Pretendemos discutir esse percurso para criar arte visual e as suas reverberações para a docência em Arte. De caráter híbrido e contemporâneo, essa iniciativa busca bases teóricas em Ostrower (2007), Duarte Jr. (1981), Barba (1994), Dias e Irwin (2013), Le Breton (2012) Deleuze e Guattari (1991). O estudo permite vislumbrar possibilidades híbridas para o desenvolvimento de percursos de criação artística, partindo de bases corporais, expandindo discussões para o campo da poética e educação estética na docência em Arte.
\end{abstract}

Palavras-chave: arte visual, dilatação corporal, docência, corpo, processo criativo.

\title{
Abstract
}

In this text, a teacher/artist/researcher's body triggers a process of creation. This is our place of departure and, at the same time that we create, we go through the reflective concepts of research in art and education. This study explores the potentialities of the body in a creative process that derives from the concept of body expansion to trigger the creation of visualities. We aim to discuss this path to create visual art and its reverberations for teaching Art. Of a hybrid and contemporary character, this initiative seeks theoretical bases in Ostrower (2007), Duarte Jr. (1981), Barba (1994), Dias and Irwin (2013), Le Breton (2012), and Deleuze and Guattari (1991). This study allows us to envisage hybrid possibilities for the development of trajectories of artistic creation, starting from bodily foundations, expanding the discussions to the field of poetics and aesthetic education in Art teaching.

Keywords: visual art, body expansion, teaching, body, creative process. 


\section{Mapa inicial}

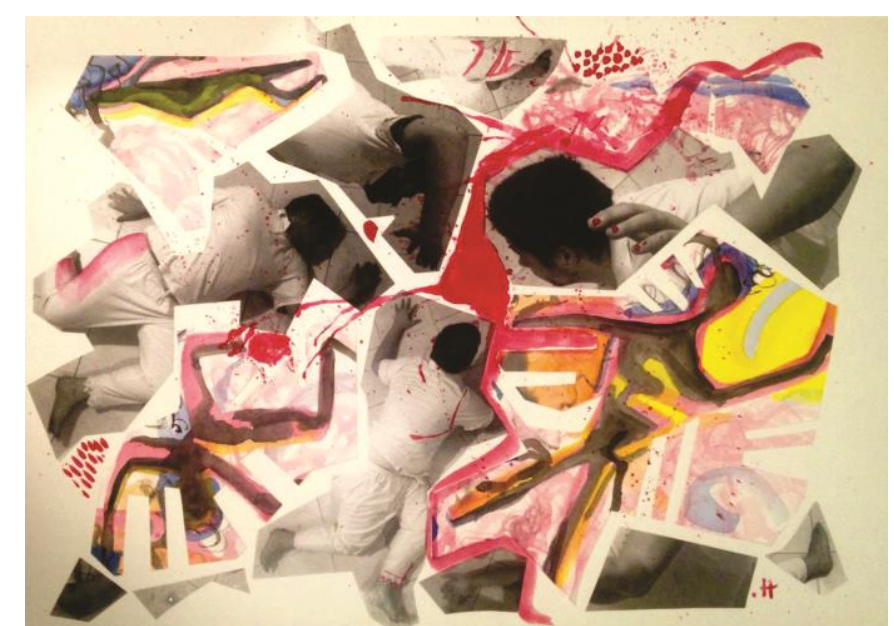

Figura 01. Sem título. Tam: 30x45. Ano: 2017 Fonte: Dilatação Corporal, Pedro Gottardi, 2017.

Partimos de uma imagem, um mapa do corpo performático. Um mapa sem um único lugar de acesso, mas com diversas possibilidades de entradas e de saídas para se pensar um percurso no qual o corpo é o tema, o suporte e o lugar da experiência. Compreendemos o corpo como algo vivo, visceral. Aqui, nesse caso, um corpo de professor/artista/pesquisador que se coloca em processo de criação. Esse é nosso lugar de partida e, ao mesmo tempo, lugar de trajeto, entendendo que a pesquisa se dá no percurso e que o processo criativo e estético é sustentado nesse contexto de experiências. Nosso Grupo de Pesquisa em Arte e Estética na Educação vem investigando processos de educação estética e mediação cultural em contextos de educação formal e não formal. Nessa trajetória vimos pensando os processos de formação docente e como esses sujeitos professores que também vivem e experienciam a arte se percebem nesse percurso.

A imagem da Figura 1 desloca-nos a uma trajetória específica (mas poderia ser muitas) de um professor/artista que se olha e que busca no seu corpo possibilidades de criação e de pesquisa em educação em sua poética. O grupo volta seu olhar para esse percurso poético, para tentar perceber o que atravessa ou afeta esse sujeito enquanto seu corpo vibra e se dilata. O professor/artista chama esse processo de "dilatação corporal", e, com ele, coautor desse texto, vamos olhar para o processo para juntos buscar esses pontos que podemos, na linguagem visual, compreender como dilatação. O que nos interessa? Um processo de pesquisa e linguagem em arte e educação estética híbrido, entrelaçado e com múltiplas conexões. 


\section{Dilatação dos caminhos...}

Ao pensarmos no corpo como espaço para a busca de possibilidade de criação visual, deparamo-nos com as dimensões subjetivas e sociais que o próprio corpo carrega. 0 corpo é campo dos afetos, do sentimento, das emoções, das vibrações, dos símbolos e dos valores antropologicamente construídos ao longo da história da humanidade (ZANELLA; PERES, 2017). O potencial para a criação em arte parte da possibilidade do corpo em mobilizar as dimensões sensíveis, na busca de memórias das experiências construídas ao longo da existência. Desde épocas remotas, o corpo estabelece a materialidade da relação com o mundo e possibilita a "[...] expressão dos sentimentos, cerimoniais dos ritos de interação, conjunto de gestos e mímicas, produção da aparência, jogos sutis da sedução, técnicas do corpo, exercícios físicos, relação com a dor, com o sofrimento, etc." (LE BRETON, 2012, p. 7).

Em se tratando da arte, o corpo permanece um campo misterioso que mobiliza atos de criação nos espaços de existência, de presenças e de ausências, da experiência e da memória em intensas conexões com a constante mutabilidade da vida. Compreendemos esse corpo como materialidade criativa, que, na relação com suas dimensões subjetivas, se expande para além das aparências imagéticas e adentra o campo dos percursos de criação visual.

Este estudo pretende embrenhar-se nos campos das potencialidades do corpo em uma possibilidade criativa na intersecção das dimensões do artista/docente/pesquisador. Aqui, adotamos o conceito de dilatação corporal (BARBA, 1994; FERRACINI, 2001), para desencadear o percurso de criação artística. O corpo em ação, dilatando os sentidos, músculos, fluídos, ossos, pele e mente para atingir um estado performático de liberdade criativa. Assim, partimos de nossas inquietações artísticas, principalmente em poéticas do corpo em percursos de criação. A principal questão abordada aqui está em: Quais as potências do corpo para a criação visual partindo da performance e do conceito de dilatação corporal para pensar a docência em arte?

Nossa intenção é estender os olhares para o percurso criativo que se inicia com a performatização do corpo, buscando a dilatação muscular inspirando a criação de arte visual. Para isso, adotamos o percurso do artista visual Pedro Gottardi na criação da série "Dilatação Corporal" para tecer reflexões em torno da criação como espaço para pensar a ação docente em arte. Outro suporte conceitual relevante para este estudo está na Pesquisa Educacional Baseada em Artes - PEBA (DIAS; IRWIN, 2013; OLIVEIRA, 2013;

Revista Digital do LAV - Santa Maria - vol. 11, n. 3, p. 47 - 66 - set./dez. 2018 ISSN 1983 - 7348 
CARVALHO; IMMIANOVSKY, 2017), que permite a inserção das linguagens da arte em percursos de pesquisas educacionais ou em possibilidades para pensar percursos criativos conectados à produção e ao conhecimento acadêmico.

Nessa perspectiva, as identidades de artista, pesquisador e professor podem estar intimamente conectadas durante percursos de pesquisa envolvendo arte, de modo que permeiam a estrutura investigativa com intensidades, inserções, criações, discursos artísticos com o rigor necessário para a produção de conhecimento em arte e educação (CARVALHO; IMMIANOVSKY, 2017). Dessa forma, a PEBA abre espaço para que as especificidades das linguagens artísticas assumam lugar importante nos ambientes de produção do conhecimento. Significa incluir a arte como campo de conhecimento a ser explorado.

Para mapear os indicativos da criação inspirada na dilatação corporal, apropriamo-nos do conceito de cartografia (DELEUZE; GUATARRI, 1991; URIARTE, 2017). Esse conceito estabelece olhares sensíveis para o percurso de pesquisa considerando as inserções, as singularidades, as particularidades do símbolo estudado. Os caminhos para a criação de arte recebem destaque, como um mapa, em que é marcado por intersecções das múltiplas informações que o percurso pode mostrar. O traçado do mapa são caminhos com infinitos pontos que permitem chegadas e partidas de modo a conectar-se com a temática de estudo (URIARTE, 2017).

De modo a adentrar nossas bases conceituais, passaremos ao próximo espaço cartográfico. Os conceitos conectam-se para sustentar a discussão teórica deste estudo e os modos de pensar o percurso criativo em arte como campo de produção de conhecimento que permitem o acesso a novas poéticas do corpo em arte. Adiante mais uma parada, um acesso, outras conexões para um campo conceitual pouco explorado.

\section{Caminho conceitual}

O caminho de pesquisa está marcado pela Arts-Based Research (ABR), que, nos campos de pesquisa no Brasil, denomina-se Pesquisa Baseada em Arte (PBA), ou como Pesquisa Educacional Baseada em Arte (PEBA), ou, ainda, como Investigação Educacional Baseada em Arte (IEBA) (OLIVEIRA, 2013). Nessa abordagem de pesquisa com bases fenomenológicas, no Estruturalismo e Pós-estruturalismo, lançam-se olhares para o que é diferente, questionando "narrativas totalitárias sobre o saber" (OLIVEIRA, 2013, p. 3) que prevalecem em percursos de produção de conhecimento no Brasil. Originalmente, a PEBA possui suas raízes nos estudos e nas sistematizações de Elliot Eisner, desenvolvidos nos anos de 1970-1980, na Stanford University (EUA) em cursos de Pós-Graduação. A

Revista Digital do LAV - Santa Maria - vol. 11, n. 3, p. 47 - 66 - set./dez. 2018 ISSN 1983 - 7348 http://dx.doi.org/10.5902/1983734832832841 
abordagem foi instituída na Faculdade de Educação da Universidade da Columbia Britânica, UBC (Canadá), ramificando-se em outras instituições e programas de Graduação e Pós-Graduação (DIAS, 2013).

Ao buscar possibilidades de inserção das linguagens da arte em pesquisas educacionais, Eisner integrou arte não só como objeto de estudo e campo de produção de conhecimento em percursos de pesquisa acadêmica (IRWIN, 2013; OLIVEIRA, 2013; DIAS, 2013; CARVALHO; IMMIANOVSKY, 2017). "A PEBA configura-se como perspectiva metodológica que utiliza processos e produtos artísticos, estéticos por natureza, para investigar, problematizar e compreender questões educacionais" (CARVALHO; IMMIANOVSKY, 2017, p. 226). Nessa abordagem, destaca-se a A/r/tografia, "[...] que incorpora especificamente os procedimentos e as atividades artísticas - fazer artístico no processo de investigação" (CARVALHO; IMMIANOVSKY, 2017, p. 224).

O conceito de $\mathbf{A} / \mathbf{R} /$ Tografia está conectado ao entrelaçado de identidades no percurso de desenvolvimento de conhecimento envolvendo arte. "A/R/T é uma metáfora para:

Artist (artista), Researcher (pesquisador), Teacher (professor) e graph (grafia: escrita/representação). Na a/r/tografia saber, fazer e realizar se fundem" (DIAS, 2013 , p. 25, grifos nossos). A A/r/tografia inseriu-se em contexto de produção de conhecimento no Brasil, principalmente em pesquisas educacionais, por meio do professor Belidson Dias, da Universidade de Brasília, e da professora Rita Irwin, da University of British Columbia. Eles organizaram diversos estudos em torno da PEBA$A / r$ tografia que resultou em uma publicação pela editora da Universidade Federal de Santa Maria chamada Pesquisa educacional baseada em arte: a/r/tografia. Na abordagem artográfica, a produção do conhecimento conecta-se a atos de criação e de recriação de si mesmo ao "intuir, o sentir e o pensar" (IRWIN, 2013, p. 184) no percurso de investigação. Dessa forma, o pesquisador torna-se o criador de propostas artísticas e também está inserido no percurso de pesquisa. "É por isso que, na A/r/tografia, o fazer artístico torna-se fundamental, pois é deste e por este que o conhecimento se constrói" (CARVALHO; IMMIANOVSKY, 2017, p. 230).

A cartografia também influencia os modos de conduzir o percurso deste estudo. Como um mapa, o percurso de pesquisa aponta intersecções que se tornam elementos que compõem a pesquisa. No campo das artes, a cartografia permite desenhar o percurso indicando as linhas de acesso e as conexões do ato criativo. As linhas que conectam os signos estéticos abrem-se para reflexões em torno das dimensões da pesquisa, mantendo aberta a possibilidade de novos caminhos. Para Uriarte (2017), o mapa cartográfico forma uma imagem e

Revista Digital do LAV - Santa Maria - vol. 11, n. 3, p. 47 - 66 - set./dez. 2018 ISSN 1983 - 7348 http://dx.doi.org/10.5902/1983734832832841 
[...] pode ser pensado como um objeto estético que carrega formas e cores, aberto a diferentes caminhos, passível de interpretações poéticas, marcadas pela ocupação e pela desocupação de um espaço, que abriga crenças e valores culturais e sociais (URIARTE, 2017, p. 41-42).

Ao compreendermos o professor como um importante agente de mediação cultural, que decide os percursos de criação e de produção do conhecimento, a "[...] mediação com a cultura, entendida como um campo expandido para experiências estéticas" (MARTINS, 2014 , p. 17) permite perceber o professor como um sujeito que lida com a experiência artística no seu fazer, no pesquisar em processos de ensino. Nessa proposta poética, a identidade de artista está intimamente conectada à de professor e à de pesquisador, ao ponto de ser impossível desconectá-las.

Os processos criativos constituem espaços de pesquisa para a compreensão da criação humana e é questão que merece destaque na promoção de percursos criativos na prática profissional docente. Ostrower (2007) defende que criar é basicamente formar, transformar, modificar, dar um novo sentido. Assim, para constituir um processo de criação, precisamos conhecer as propriedades dos diversos materiais e das ferramentas que materializam e auxiliam no desenvolvimento de arte.

Nesse sentido, a arte concentra, em sua natureza, múltiplos sentidos que existem apenas nela mesma. No momento da contemplação, a arte afeta-nos de forma que pode provocar "[...] determinados sentimentos intraduzíveis, indizíveis e inexprimíveis, a não ser através dela própria" (DUARTE JR., 1981, p. 76). Compreender os mecanismos para criação apresenta-se como alternativa importante para a constituição profissional docente, pois a obra de arte é

[...] é sempre a expressão de sentimentos, porém uma expressão diferente de um grito ou de um gesto. É a expressão lavrada, concretizada numa forma, que adquire quase que o estatuto de um símbolo. Toda obra de arte é uma forma; nas artes "dinâmicas", como a música, a dança, teatro, etc., as formas construídas são formas dinâmicas - formas que se dão no tempo. Ao criar uma forma para ser percebida, o artista constrói com ela como que uma visão direta dos sentimentos. Como vimos, é impossível descrever os sentimentos através da linguagem discursiva; porém, na arte, os sentimentos se concretizam em formas, podendo ser percebidas. Mas, cuidado: não se pode considerar a arte como um símbolo idêntico aos linguísticos, que transmitem significados. A arte nunca significa nada fora de si mesma (DUARTE JR., 1981, p. 75, grifos do autor).

As conexões estabelecidas pelo corpo do sujeito criador e o que surge dessa relação é que podemos considerar como produto criativo. Ao mencionarmos a palavra "criatividade", as lembranças relacionadas aparecem como imagens de trabalhos belos e 
complexos que somente pessoas dotadas de algum dom podem executar. Geralmente, conectamos criação à área das artes visuais, porém é preciso reconhecer que atos de criação não se restringem à área das artes, mas às ações do ser humano em criar algo novo partindo de múltiplos materiais e processos que mobilizam fatores, experiências, estímulos, estudos e sensibilidades. Para Ostrower (2007, p. 166): "Criar pode ser tão difícil ou tão fácil como viver. E do mesmo modo necessário".

Ostrower (2007) defende que, no processo de criação, a sensibilidade é um dos fatores fortes para desenvolver o novo, potencializando a ação de criar, dando-lhes um novo significado. Para a autora, a intuição está conectada com sensibilidade e desencadeia processos criativos. A sensibilidade determina os modos como sentimos o que está posto externamente em uma dinâmica que mobiliza as dimensões corporais, bem como os sentidos, para a produção de obras artísticas ou não. Quando o corpo transpira criação, materializando as percepções, memórias e experiências em obra, temos um novo lugar: da criação, do estado criativo que o corpo encontra no tempo e no espaço, na relação com os elementos, com os conceitos ou com as materialidades.

Mobilizar o corpo e suas dimensões sensíveis para desencadear um percurso de criação pode estabelecer espaço e condição/disposição para a criação. Essa disposição que sensibilizou o corpo influenciará na produção artística do sujeito, pois este pode estabelecer estados que façam fertilizar atos criadores. Toda criação, seja de arte, seja em outra área que envolva a criatividade, essencialmente depende da sensibilidade do sujeito - sem ela bloqueios podem ser uma barreira no processo de criação.

O ato de criar possui sua propulsão na sensibilidade que também é determinada pelas experiências; está fundamentado na intuição e no desafiar-se à criação. Sem a sensibilidade como propulsora do processo, dificilmente poderemos dar início a um ato criador. A cultura em que cada sujeito está inserido é permeada por múltiplos condicionamentos, tanto das maneiras de compreender o corpo como lugar da sensibilidade bem como local da percepção. Esses fatores influenciam nas criações, pois o sujeito, em determinado momento, precisa apropriar-se de vivências e torná-las experiências para conhecer a si próprio (LARROSA, 2002).

O ato de criar está conectado com certa ordenação de informações e elementos em uma dinâmica de construir e reconstruir o que já foi criado, ou seja, a criação possui bases no que já foi criado para então buscar o novo, cada qual na sua individualidade e com suas experiências. Quando surgem novas alternativas, permite-nos

Revista Digital do LAV - Santa Maria - vol. 11, n. 3, p. 47 - 66 - set./dez. 2018 ISSN 1983 - 7348 http://dx.doi.org/10.5902/1983734832832841 
[...] entender que o processo de criar incorpora um princípio dialético. É um processo contínuo que se regenera por si mesmo e onde o ampliar e o delimitar representam aspectos concomitantes, aspectos que se encontram em oposição e tensa unificação [...]. (OSTROWER, 2007, p. 26).

O criador está intermitentemente mobilizando suas referências que o auxiliarão no seu processo de criação, bem como os múltiplos níveis do ser sensível, cultural, do sujeito (OSTROWER, 2007). Esses fatores estão em constante interação para fazer surgir o novo, que, por sua natureza, constitui experiência da criação, que alimentará uma nova experiência. $O$ ato criador estabelece-se como um ciclo da ação humana, possibilitando conexões híbridas com linguagens e materiais para potencializar o próprio ato criativo.

Nesse sentido, a arte contemporânea instiga a hibridização de linguagens. Essa possibilidade de conectar múltiplas linguagens arte torna o resultado aberto a múltiplas interpretações, dinamiza acessos e estabelece estéticas conceituais. Para Martins, Picosque e Guerra (1998), a performance compreende a linguagem capaz de combinar, de recombinar, de associar múltiplas linguagens artísticas, dinamizando obras que podem impactar diretamente quem dela partilha.

Para Larrosa (2002, p. 21), a experiência seria aquilo que nos acontece e desse acontecimento nossas estruturas intelectuais modificam-se. Essa experiência é o que nos faz vibrar, garantindo elaborações internas que nos deslocam, nos mobilizam para além de nossas condições e contextos culturais. A experiência seria o que nos arrebata diante do algo ocorrido, e, a partir disso, não poderemos continuar sendo aquilo que éramos. Isso faz a diferença quando pensamos a formação docente, a constituição do professor de arte que, ao desafiar-se a percorrer ações criativas, se constitui artista por criar arte, constitui-se professor por compreender processos de criação, por estar apto a propor percursos criativos e organizar os achados na perspectiva de pesquisador.

Martins (2014) tece reflexões em torno do conceito de mediação cultural e o define como um encontro, como possibilidade de estar entre, de aproximar arte e o olhar do observador. É desse entre lugar que discutiremos, adiante, onde o corpo do pesquisador/artista/professor está em foco para mobilizar potências criadoras alicerçadas nas experiências e no conceito de dilatação corporal (BARBA, 1994; FERRACINI, 2001; FERREIRA JUNIOR, 2011), a qual desempenha o papel disparador de atos criativos.

\section{A dilatação corporal em percurso criativo}

O corpo, lugar da sensação, constitui lugar das possibilidades da sensibilidade e das possíveis relações com a criação de arte. O corpo como criação dos contextos culturais

Revista Digital do LAV - Santa Maria - vol. 11, n. 3, p. 47 - 66 - set./dez. 2018 ISSN 1983 - 7348 http://dx.doi.org/10.5902/1983734832832841 
está condicionado à inexistência como forma e potencialidade de criação e de recriação das realidades. Le Breton (2012) defende que o corpo não existe, é uma ficção e não é percebido como corpo. Isso aponta para a fragilidade da percepção de outros corpos com braços, pernas, cabeça e fluídos dotados de potência sensível. A dificuldade contemporânea está justamente em perceber o outro como um corpo sensível, singular e que vibra no contato com outros corpos. Para Le Breton (2012), o que temos são ideias de homens e de mulheres, em uma configuração marcada pelas questões padronizadas de gênero, sem pulsar como forma humana.

Nessa perspectiva, o corpo necessita ser visto, percebido, e, partindo das relações cotidianas, ressignificar os corpos. A arte busca no corpo espaços para a criação e inspiração para fundamentar percursos reflexivos que devolvam ao corpo a capacidade e a amplitude da capacidade de sentir, de perceber-se e de expressar-se. Enquanto no corpo múltiplas sensações acontecem desencadeadas por infinitos provocadores, ele "[...] é similar a um campo de força em ressonância com os processos de vida que o cercam" (LE BRETON, 2012, p. 26).

Quando pensamos em corpo, logo imaginamos sua forma, seus movimentos, sua presença. Aqui damos o primeiro passo para pensar as potencialidades de um corpo que pode dilatar-se para ressoar, criar, imaginar, por meio de diferentes caminhos percorridos em processos criativos de diversas linguagens de arte. Afinal, "[...] o corpo não é somente uma coleção de órgãos arranjados segundo leis da anatomia e da fisiologia. É, em primeiro lugar, uma estrutura simbólica, superfície de projeção passível de unir as mais variadas formas culturais" (LE BRETON, 2012, p. 29).

Nesse sentido, o corpo que carrega subjetividades, memórias, marcas, dores, excitações, vibrações, mutações, sons e formas, desafia-se a percorrer caminho de criação artística para materializar o sensível em visualidades. Le Breton (2012) considera o corpo uma ficção criada culturalmente e é visto "[...] como corporeidade da mesma forma que a comunidade de sentido e valor que planejou o lugar, os constituintes, os desempenhos, os imaginários, de maneira mutante e contraditória de um lugar e tempo para outro das sociedades humanas (LE BRETON, 2012, p. 32). A palavra "corpo" possui origem do latim e possui várias concepções, como aquilo que possui extensão limitada, finita, transitória, pode ser percebida pelos órgãos sensoriais. O corpo pode ser ainda uma estrutura orgânica e viva que funciona com certa interconexão e estabelece relações com outros corpos em dimensões de presenças ou ausências afetivas (PRIBERAM, 2017).

Revista Digital do LAV - Santa Maria - vol. 11, n. 3, p. 47 - 66 - set./dez. 2018 ISSN 1983 - 7348 
Nesse percurso de estudo, discutimos o corpo que se torna criador ao entrar em processo de dilatação corporal. O expandir, vibrar, aquecer as dimensões sensíveis do corpo sugere-nos a exploração do conceito de dilatação corporal. A palavra dilatação significa aumento de volume por efeito de calor (sem mudança na constituição nem acréscimo na matéria), ampliação, prolongação, propagação e expansão. O termo corporal, do latim corporalis, corresponde a corpo, que tem corpo, matéria. Quando falamos de corporal, estamos, portanto, falando de corpo que possui matéria e ocupa um espaço, que possui determinada corporalidade (PRIBERAM, 2017).

O conceito de dilatação corporal é um termo desenvolvido em pesquisas para o treinamento corporal no trabalho de ator em teatro com o objetivo de mobilizar as potencialidades de expansão e de vibração muscular, atingindo níveis de presença cênica (BARBA, 1994). A presença cênica como um conectar-se com o momento presente, um ser e estar extracotidiano, que permite também materializar uma corporalidade extracotidiana. Barba (1994) afirma que o corpo em dilatação, presente, ampliado, aquecido, permite um sentir também em estado expandido, em amplitude que ultrapassa os estados de sustentação e de ação. Desse modo, o autor afirma que o ator, ao atingir um corpo dilatado, estabelece relações e reverberações com o observador ao ponto de o manter conectado à obra de arte teatral. A dilatação corporal é técnica do trabalho de atuação que se realiza partindo de movimentações do corpo em relação ao espaço, aos estímulos rítmicos e ao próprio corpo.

Assim sendo, a primeira tarefa que um ator deve enfrentar, quando começa essa busca, é um desnudar-se, dinamizando suas energias potenciais e procurando encontrar e abrir as "portas" que o levem a um contato orgânico com sua pessoa. Ao mesmo tempo, deve "domar" essas energias em "trilhos" técnicos corpóreos, por meio de trabalhos e exercícios que possibilitem uma relação extracotidiana, portanto dilatada, com o espaço e com seu próprio corpo, in-corporando elementos objetivos que permitam uma nova relação psicofísica (FERRACINI, 2001, p. 133, grifos do autor).

Assim, a dilatação compreende o trabalho sobre si mesmo ao ampliar o modo de perceber as dinâmicas do movimento corporal. Um dos efeitos desse colocar-se no trabalho corporal é um certo aquecimento e expansão das dimensões musculares. "O corpo dilatado é um corpo quente, mas não no sentindo emocional ou sentimental. 0 corpo dilatado é acima de tudo um corpo incandescente no sentido científico do termo" (FERREIRA JUNIOR, 2011, p. 129). Esse encontro da dilatação corporal acontece por meio de exercícios em que o corpo é estimulado a encontrar essa possível dilatação. A experiência e a consciência de si mesmo representam fatores determinantes no trabalho de dilatação corporal. Assim, o praticante conseguiria ampliar, expandir, dilatar sua 
percepção corporal e, também, os modos de ser e estar em cena tendo como partida o corpo.

Para Ferracini (2001), o percurso de trabalho corporal na perspectiva da dilatação consiste em "[...] resistência musculares, oposições corpóreas, exaustão física, contatos profundos com a pessoa, os atores conseguem, depois de muitos anos de trabalho, uma dilatação, uma certa manipulação consciente da energia e suas variações" (FERRACINI, 2001, p. 108). A consciência das potencialidades corporais na perspectiva de dilatação corporal como ação de recriar-se corporalmente é abordada neste estudo como conceito disparador para a criação de visualidades. Mobilizar o corpo para percorrer percurso de criação é também criar um corpo novo. Esse recriar-se como um transbordamento de vitalidade, um expandir-se pelos espaços, é buscar a energia característica do ser humano corporificado (FERREIRA JUNIOR, 2011).

Buscamos, agora, conectar o conceito de dilatação corporal como disparador para a criação de visualidades em experimentação performática. Da experimentação da dilatação corporal, foram registradas imagens do corpo em percurso de dilatação e, após submeter as imagens a tratamento digital e impressão, realizou-se a intervenção de pintura em aquarela. Esse percurso híbrido é analisado a seguir com vistas a compreender as reverberações desse percurso nos trabalhos visuais e nas identidades professor/artista/pesquisador.

\section{Trajeto criativo: a dilatação corporal, a docência e as visualidades}

Se criar está conectado a trazer à tona novos significados, ressignificando materialidades e permitindo múltiplos sentidos (OSTROWER, 2007), buscamos estender o olhar para o percurso criativo proposto pelo artista visual Pedro Gottardi em 2017. O jovem artista busca propulsão para a criação visual em conceitos e práticas da linguagem teatral.

O início do percurso deu-se com a apropriação do conceito de dilatação. Para Barba (1994), o corpo em trabalho de dilatação proporciona ampliação de estados de presença e um aquecimento expandido, permitindo o acesso a modos de agir extracotidianos. Dessa forma, o corpo em performance expande-se estabelecendo relações com o tempo e o espaço que abrem caminho para a criação.

Pedro Gottardi, em 2017, registrou-se fotograficamente ao realizar performance art em dilatação corporal para posteriormente criar visualidades. Para desenvolver a materialidade na pesquisa, diversas etapas foram necessárias. Encontramos um processo de criação em que a performance art é disparador criativo; o corpo transforma-se no

Revista Digital do LAV - Santa Maria - vol. 11, n. 3, p. 47 - 66 - set./dez. 2018 ISSN 1983 - 7348 
suporte para imprimir as reações que são registradas pela fotografia durante a ação performática. O corpo é conduzido em sua ação a partir de estímulos áudio visuais, sem controlar a movimentação, permitindo a vazão de desejos e as vontades direcionados à criação artística.

Nesse percurso investigativo, surge uma encruzilhada, com muitas perguntas e poucas respostas em um corpo que fala, desnuda-se e evidencia seu existir potente e político. Em uma questão sociológica, segundo Le Breton (2012, p. 32), "[...] 'corpo' é uma ficção; mas ficção culturalmente eficiente e viva". Nessa perspectiva ficcional do corpo, a ideia dos modos de exposição dos corpos está conectada aos modos de configurar, formar, conceber e agir. O corpo é algo que, ao mover-se, afeta outros corpos e também está exposto para ser igualmente afetado.

Desafiar-se ao ato criativo implica em estar precariamente mobilizando as dimensões corporais para que se permita novas configurações do espaço criativo. A poiésis como lugar do ato criativo desponta, nesse percurso, em momentos distintos, e o corpo do artista/pesquisador/docente está em permanente condição de criação. A identidade docente conecta-se às identidades de artista e de pesquisador em uma dança da criação performática-visual. As etapas da poética performática da criação visual de Gottardi perpassaram a performance art, a fotografia e o vídeo, a edição gráfica, a impressão em papel, a intervenção plástica, a digitalização e a impressão em diversos suportes.

Na performance art, o teor ritualístico está presente ao permitir-se desencadear dilatações musculares, mentais e de fluxos criativos. Os limites temporais dissolvem-se em rítmicas corpóreas e a relação estética passa a ser ritualizada, deslocando as dimensões da interação (COHEN, 2007). Por estímulos próprios, menos racionais, o movimento corporal conduz para espaços da percepção e registro das qualidades físicas que surgem. Ao final, é suspenso por uma constate conexão com si mesmo e respostas que surgem do próprio corpo em dilatação.

O corpo performático desafia a própria estrutura física e mental ao permitir que o foco seja a materialidade corpórea e não as condições abstratas de pensamento. O espaço da dilatação corporal permite expandir as noções corporais e lançar olhares para a constituição docente na medida em que expande os modos de percepção de si mesmo em relação à performance art. O primeiro indício de criação visual foi por meio de fotografia e vídeo. A câmera foi posicionada antes do início da performance. A fotografia foi realizada pela equipe de apoio durante o percurso e as imagens geradas passaram por edição gráfica e receberam alguns filtros para produção de efeitos gráficos.

Revista Digital do LAV - Santa Maria - vol. 11, n. 3, p. 47 - 66 - set./dez. 2018 ISSN 1983 - 7348 http://dx.doi.org/10.5902/1983734832832841 

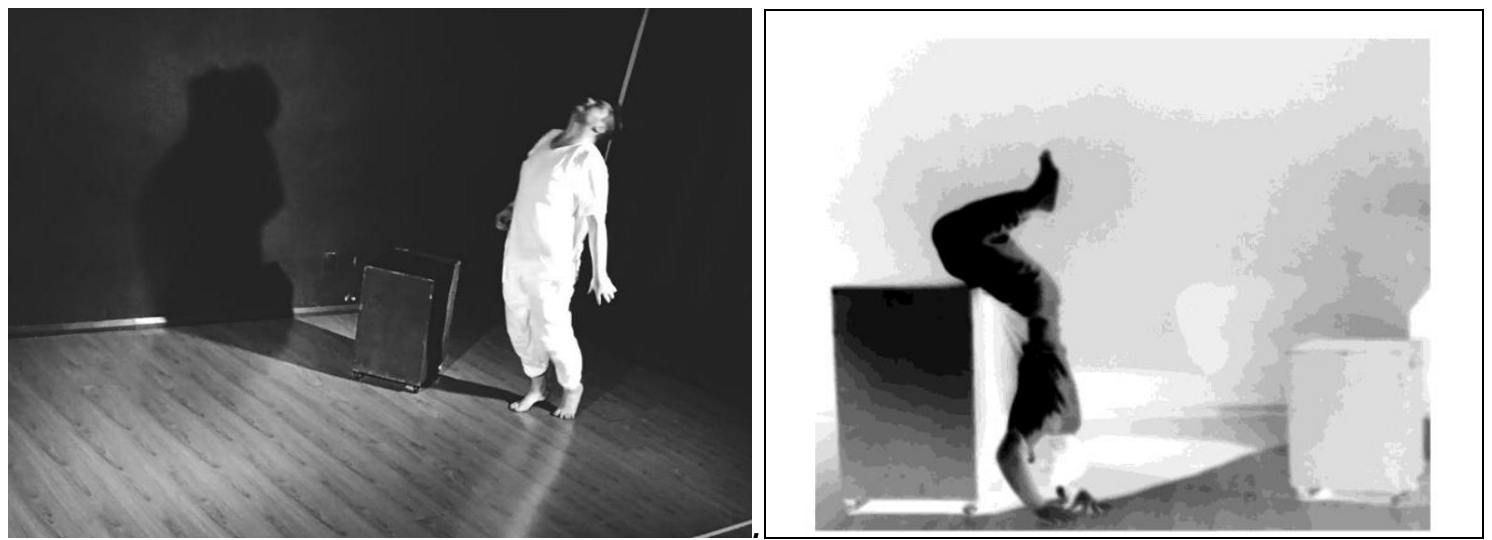

Figuras 02 e 03. Registro fotográfico da performance Fonte: Acervo dos autores (2017).

O passo seguinte foi a impressão à laser em papel para que se pudesse aplicar elementos visuais. Nesse momento, o corpo reaparece como espaço para a ação criativa. Com as imagens impressas, o corpo estabelece relação com sua imagem. O corpo que anteriormente foi material para a criação performática de visualidade, pôde observar a sua imagem e estabelecer outros lugares para a criação. $O$ olhar percorreu as fotografias e desencadeou a memória corporal do momento performático e, dessa memória, surgiram as sensações e o desafio de transpor para a visualidade tais sensações.

A aquarela, a tinta acrílica, os recortes são recursos que permitem o surgimento de novos signos e significados. Essa etapa também configura um terceiro momento de criação: o corpo do artista/pesquisador/professor mobilizando visualidades e sentidos que surgiram da performance art. E, por fim, o resultado foi digitalizado para que assim pudesse ser impresso em diversos suportes.

Revista Digital do LAV - Santa Maria - vol. 11, n. 3, p. 47 - 66 - set./dez. 2018 ISSN 1983 - 7348 


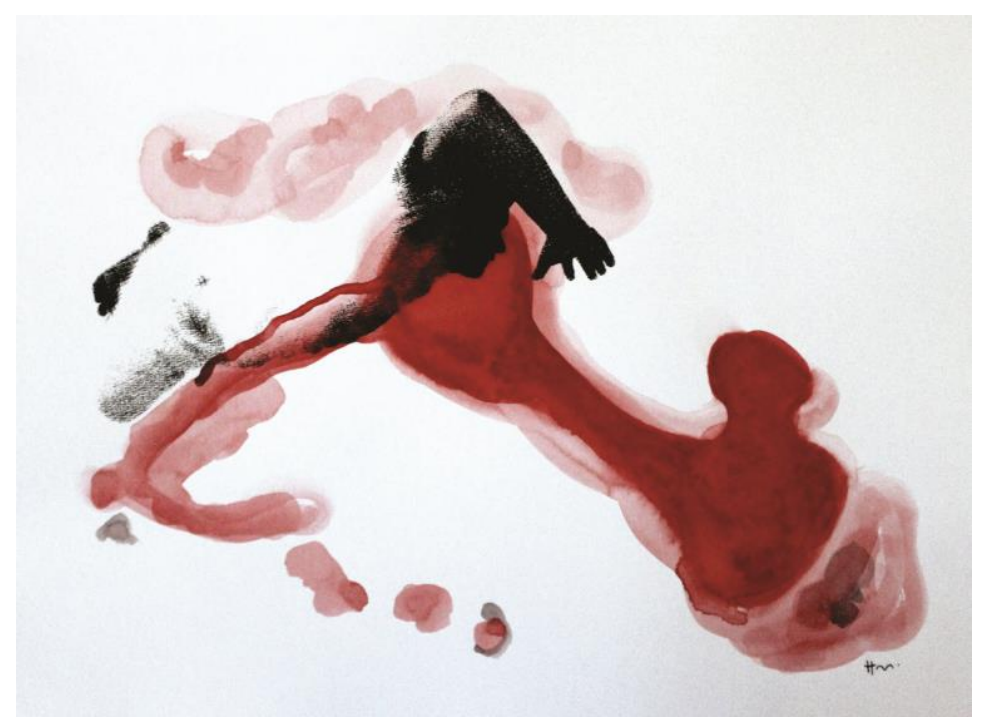

Figura 04. Sem Título. Técnica: mista. Suporte: tecido; Ano: 2017; Dimensões: 59x84 cm Fonte: Acervo dos autores (2017).

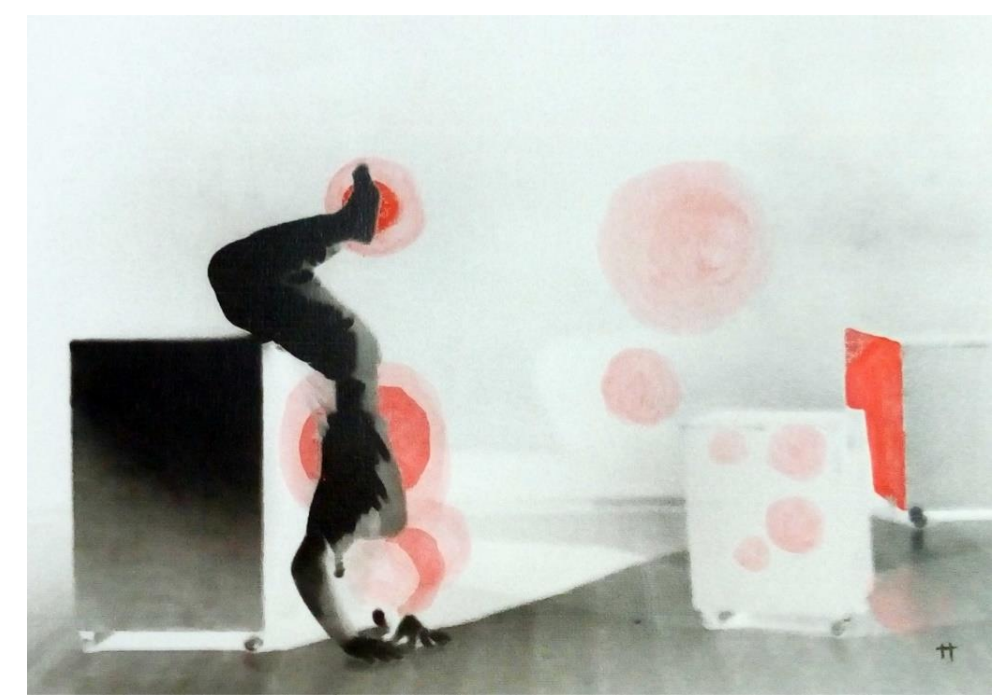

Figura 05. Vocifera. Técnica: mista. Tam.: 14x14cm. Ano: 2017 Fonte: Acervo dos autores (2017).

O corpo em trabalho de dilatação percorre o caminho das expansões musculares, estados de exaustão física; é um trabalho sobre si mesmo ao ponto de, depois de algum tempo, o praticante pode dinamizar as potencialidades para a atuação em teatro (FERRACINI, 2001). Assim, o corpo posto em trabalho de dilatação desencadeou potencialidades para a criação presentes na sensibilidade da carne e da mente. Nesse sentido, a proposta 
acena para possíveis ações educativas utilizando registros fotográficos em contexto escolar.

O percurso de dilatação corporal permitiu o contato com as dimensões de si mesmo, mobilizando inspirações e materialidades para a criação visual. Por seu caráter de expansão da consciência de si mesmo e das potencialidades criativas, é que a dilatação corporal funciona como disparador das sensações e intensidades que podem variar de acordo com a disponibilidade do pesquisador. Esse campo expandido para a experiência estética no corpo do docente implica na ampliação da percepção de que o professor é promotor do fazer artístico em processos de ensino. Dessa forma, o professor/pesquisador experimenta ser criador de percursos de criação em arte que constroem saberes, tanto para sua prática docente quanto para os estudantes (CARVALHO; IMMIANOVSKY, 2017).

O percurso de criação do artista Gottardi é metáfora para analisar a conexão entre o corpo e as visualidades que surgiram por meio da performatização dilatada corporalmente. Tendo em vista que as visualidades que surgiram nos trabalhos visuais do artista são extensões do percurso corporal restabelecido em performance art, a dilatação funcionou como campo de expansão do corpo, de um prolongamento do corpo, de uma ampliação daquilo que é visível como corpo, mobilizando o que não é visível, para então transformar corpo expandido em visualidade e vibração pictórica.

Como mencionamos anteriormente, o resultado do trabalho possui abordagem contemporânea pelo seu caráter híbrido. As fotografias que surgiram da performance receberam tratamento digital, foram impressas em papel tamanho A3 e, para produzir efeitos da dilatação nas imagens tratadas, o artista utilizou a tinta aquarela na cor vermelha. Aparentemente, a vibração do vermelho que remete à matéria viva estabelece relação direta com o corpo que possui vida latente. As formas do corpo parecem compor certa dinâmica em relação ao cenário onde o pigmento vermelho foi aplicado. A sobreposição do vermelho ao corpo estabelece a presença da vibração experimentada performaticamente em exercício de dilatação corporal. A suavidade das pinceladas também intensifica a presença de um corpo que mapeou as potências existentes em dilatação para, depois, transformá-las em visualidade.

O corpo em percurso de dilatação das potencialidades busca outros sentidos para o ser e estar na criação de arte, dialogando com as dimensões internas na busca do novo como lugar para a criação. Um encontro com novas possibilidades de um corpo em diálogo com as dimensões do próprio corpo que busca criar o novo e se mostra em exposição total

Revista Digital do LAV - Santa Maria - vol. 11, n. 3, p. 47 - 66 - set./dez. 2018 ISSN 1983 - 7348 http://dx.doi.org/10.5902/1983734832832841 
(COHEN, 2007). Se o corpo é espaço para a sensibilidade, é por meio da dilatação das dinâmicas da vibração corporal que se pode inspirar uma produção artística tão viva quanto é o corpo. Esse corpo abre-se para que o novo possa existir, é uma nova ordem, outra significação - como em uma respiração, como o ritmar do coração que estabelece a expansão dos fluídos, a dilatação oferece a expansão da criação (OSTROWER, 2007).

Nesse sentido, o corpo presente na dimensão do aqui-agora representa a concentração das potencialidades corporais para a criação artística. Esse aspecto traz para a discussão as possibilidades criadoras necessárias para a docência em arte. A experiência de possibilitar ao corpo traçar percursos de criação traz à discussão a necessidade de o docente em arte compreender as dimensões corporais em processos de criação, bem como abrir espaços para a criação em arte.

A conexão com o aqui e o agora é um recurso que se concentra no ato criativo e na dilatação do corpo como disparador de presenças e ausências do fazer artístico. Ao utilizar a aquarela vermelha para materializar no papel uma forma, significa a expansão das experiências do corpo em comunicação dos afetos subjetivos. A dilatação funciona como metáfora para que o corpo possa explorar novas maneiras de ser e estar na vida; um dilatar de pensamento criativo expresso em arte, assim como a performance art, cuja perspectiva ritualística estabelece conexões expandidas entre tempo e espaço (COHEN, 2007).

Assim, pesquisar as possibilidades corporais para a criação representa um lançar-se para o campo da criação artística, entrelaçando as dimensões do artista, do pesquisador e do docente. Se, no corpo, localizamos a fonte de toda a criação artística, é por meio dele que toda criação se torna viva e materializa-se em um estado de presença. Essa presença desencadeada pelos estímulos da dilatação do próprio corpo abre interfaces para outras conexões. Para Duenha e Nunes (2017):

Uma presença-convite seria essa que se permite uma contaminação constante, seja em seus modos de fazer/treinar, anteriores ao encontro, seja no que se conhece por estado de presença e que, livre de mistificações, passa a ser simplesmente o estar com o outro na arte, com poros dilatados, receptivos aos afetos. Assim, delinearíamos uma noção de presença na arte como algo que não se faz só (DUENHA; NUNES, 2017, p. 114).

Nessa perspectiva, a capacidade do corpo de expandir-se e atingir um estado de dilatação dos poros a fim de estabelecer conexões com outros corpos, de ser afetado e de afetar outros corpos está intimamente ligado às práticas de colocar-se em percurso criativo. O estar em dilatação do corpo pulsante representa também um novo ser e estar 
em vida, afetar-se pelo pulsar da vida e ressoar em outros corpos por meio da criação artística. O trabalho de Pedro Gottardi traz a vibração do corpo que, ao dilatar-se, materializou-se em forma, em sensação e em objeto estético, permitindo múltiplas afetações aos corpos de quem o observa.

\section{Inconclusões e expansões}

Ao estabelecer um momento de conclusão do pensamento, permitimo-nos considerar as vibrações deste estudo para além da percepção conceitual e localizarmos as potencialidades do percurso criativo do corpo em dilatação/expansão como principal achado. O corpo em performance busca expandir sua materialidade, seus fluidos, suas sensações, suas energias e seus pensamentos, afetando o observador em múltiplas aberturas. A dilatação corporal é um ponto de partida para múltiplas chegadas e, também, inúmeras inserções no ato de criar. Desse modo, esse percurso de estudo evidencia uma possível abordagem híbrida para um trajeto de ensino e aprendizagem em arte, tendo o corpo como principal elemento disparador da criação. Ao mesmo tempo que o corpo se torna suporte, é objeto de estudo como propulsor das potências da vida para a criação de arte.

Ao observarmos a produção do artista Pedro Gottardi, percebemos a vibração das cores e das formas que surgiram de um processo híbrido, conectando linguagens da arte. Adotar - conceito de dilatação corporal, de linguagem teatral, para impulsionar performaticamente o corpo, possibilitou mobilizar potências criativas. O registro da performance foi realizado com recurso fotográfico, para, posteriormente, as imagens receberem tratamento digital e, por fim, serem impressas em papel, e, por meio de pintura, as obras da série "Dilatação Corporal" surgiram.

Esse percurso mostra a versatilidade da arte contemporânea para desencadear percursos de experimentação e de criação artística. O corpo mobilizou sua materialidade e fisicalidade para também mobilizar o invisível do corpo. Essas dimensões materializaramse em forma de linguagem fotográfica e pintura. As pinceladas de aquarela vermelha traduzem as expansões do corpo em formas, que, por sua vez, vibram no corpo do observador, expondo as reverberações para a docência em arte como principal condição reflexiva.

O corpo em percurso de dilatação permite romper com o condicionamento das potencialidades criativas que os mecanismos sociais abortam. A obra representa um diálogo direto com o que a experiência fez reverberar no corpo do criador ao ponto de remeter-nos ao corpo expandido. As formas materializam o expandir do corpo posto em

Revista Digital do LAV - Santa Maria - vol. 11, n. 3, p. 47 - 66 - set./dez. 2018 ISSN 1983 - 7348 
processo de criação e confirmam a potência das suas dimensões para a criação de visualidades.

Esse percurso ainda nos sugestiona 0 entrecruzamento das identidades de artista/professor/pesquisador. $O$ artista acessa seus labirintos corporais em performance de dilatação corporal, ao mesmo tempo que o pesquisador mobiliza reflexões conceituais acerca do percurso de criação, e o professor apropria-se do processo criativo para propor a criação artística com estudantes. Dessa forma, a indissociabilidade das três identidades em contextos de pesquisa em educação define os modos de conduzir investigações na criação de arte.

As dimensões do corpo na criação artística são despertadas pela dilatação da dimensão física, e a expansão permite recrutar as dimensões invisíveis que podem resultar em arte. O maior desafio de cada criador é traçar e percorrer seu próprio percurso, de acordo com suas subjetividades, de criação artística como alternativa para a recriação de si mesmo, da descoberta de potencialidades do corpo e das possibilidades para despertar potência da criação em estudantes de diversos níveis.

\section{Referências}

BARBA, Eugenio. A canoa de papel: tratado de antropologia teatral. São Paulo: Hucitec, 1994.

CARVALHO, Carla; IMMIANOVSKY, Charles. PEBA: a arte e a pesquisa em educação. Revista Reflexão e Ação, Santa Cruz do Sul, v. 25, n. 3, p. 221-236, set./dez. 2017.

COHEN, Renato. Performance como linguagem: criação de um tempo-espaço de experimentação 2. ed. São Paulo: Perspectiva, 2007.

DELEUZE, Gilles; GUATTARI, Félix. Mil platôs I: capitalismo e esquizofrenia. Tradução Aurélio Guerra e Cecília Pinto Costa. Rio de Janeiro: 34, 1991.

DIAS, Belidson. A/r/tografia como metodologia e pedagogia em artes: uma introdução. In: DIAS, Belidson; IRWIN, Rita. (Orgs.). Pesquisa Educacional Baseada em Arte: A/r/tografia. Santa Maria: UFSM, 2013. p. 21-26.

DIAS, Belidson; IRWIN, Rita. (Orgs.). Pesquisa Educacional Baseada em Arte: A/r/tografia. Santa Maria: UFSM, 2013. 
DUARTE JR., João Francisco. Fundamentos estéticos da Educação. São Paulo: Cortez, 1981.

DUENHA, Milene Lopes; NUNES, Sandra Meyer. Presença que não se Faz Só: potências de afeto no ato de com-por entre corpos. Revista Brasileira de Estudos da Presença, Porto Alegre, v. 7, n. 1, p. 99-122, jan./abr. 2017.

FERRACINI, Renato. A arte de não interpretar como poesia corpórea do ator. Campinas: UNICAMP; FAPESP: Imprensa Oficial do Estado de São Paulo, 2001.

FERREIRA JUNIOR, Antonio Marcos. A dança dos orixás de Augusto Omolu e suas confluências com a antropologia teatral. 2011. 138 f. Dissertação (Mestrado em Linguística, Letras e Artes) - Universidade Federal de Uberlândia, Uberlândia, 2011.

IRWIN, Rita L. Visões e entrevisões: por uma estética de desdobramentos do currículo. In: DIAS, Belidson; IRWIN, Rita L. (Orgs.). Pesquisa educacional baseada em arte: a/r/tografia. Santa Maria: UFSM, 2013. p. 183-195.

LARROSA, Jorge. Literatura, experiência e formação. In: COSTA, M. V. Caminhos investigativos. Rio de Janeiro: DP\&A, 2002. p. 133-160.

LE BRETON, David. A sociologia do corpo. 6. ed. Petrópolis: Vozes, 2012.

MARTINS, Mirian Celeste. Entre nuvens de tempos vividos. In: MARTINS, Mirian Celeste. (Org.). Pensar juntos mediação cultural: (entre)laçando experiências e conceitos. São Paulo: Terracota, 2014. p. 15-18.

MARTINS, Mirian Celeste; PICOSQUE, Gisa; GUERRA, Maria Terezinha Telles. Didática do ensino de arte: a língua do mundo: poetizar, fruir e conhecer arte. São Paulo: FTD, 1998.

OLIVEIRA, Marilda Oliveira de. Contribuições da perspectiva metodológica 'Investigação baseada nas artes' e da a/r/tografia para as pesquisas em educação. In: REUNIÃO NACIONAL DA ANPED, 36., 2013, Goiânia. Anais eletrônicos... Goiânia: UFG, 2013. Disponível em: <http://36reuniao.anped.org.br/pdfs_trabalhos_aprovados/gt24_trabalhos_pdfs/gt24_27 92_texto.pdf>. Acesso em: 25 maio 2018.

OSTROWER, Fayga. Criatividade e processos de criação. 6. ed. Petrópolis: Vozes, 2007.

Revista Digital do LAV - Santa Maria - vol. 11, n. 3, p. 47 - 66 - set./dez. 2018 ISSN 1983 - 7348 http://dx.doi.org/10.5902/1983734832832841 
PRIBERAM. Dicionário. Dicionário Priberam da Língua Portuguesa. 2017. Disponível em: <https://www.priberam.pt/dlpo/>. Acesso em: 25 maio 2018.

URIARTE, Mônica Zewe. Escola, música e mediação cultural. Curitiba: Appris, 2017.

ZANELLA, Andrisa Kemel; PERES, Lúcia Maria Vaz. No entrecruzamento de linguagens... a arte e o corpo para pensar a educação e a formação do humano. Revista Brasileira de Educação, Rio de Janeiro, v. 22, n. 68, p. 101-121, 2017.

\begin{abstract}
i Bolsista CAPES (Coordenação de Aperfeiçoamento de Pessoal de Nível Superior) no Programa de Pós-graduação Mestrado em Educação da Universidade Regional de Blumenau (FURB). Possui Licenciatura em Artes Visuais - FURB (2016). Bacharel em Teatro - FURB (2007). Especialista em Arte na Educação Infantil e Anos Iniciais (2012). Especialista em Gênero e Diversidade na Escola - UFPR (2016). Foi bolsista do Programa Institucional de Bolsa de Iniciação à Docência (PIBID) no subprojeto Interdisciplinar Direitos Humanos (2014-2015). Integrante do Grupo de Pesquisa em Arte e Estética na Educação. Possui experiência como ator de teatro e professor de Artes Visuais e Teatro.
\end{abstract}

ii Doutora em Educação pela Universidade Federal do Paraná (2008). Mestre em Educação pela Universidade do Vale do Itajaí (2003). Possui graduação em Licenciatura Plena Em Educação Artística pela Universidade Regional de Blumenau (1998). Atua como professora no Programa de Pós-Graduação em Educação na Universidade Regional de Blumenau (FURB) e na graduação em Cursos de Formação de Professores e Design. Tem experiência na área de Educação, com ênfase em Educação, atuando principalmente nos seguintes temas: arte, arte na educação, currículo, artes visuais e formação de professores. Líder do Grupo de Pesquisa em Arte e Estética na Educação.

iii Bolsista de Iniciação Científica - PIBIC (2018-2019). Acadêmico do curso de Licenciatura em Artes Visuais da Universidade Regional de Blumenau - FURB. Artista Plástico. Ator de Teatro. Cenógrafo. Escultor. Performer. Professor de Arte da rede Municipal de Educação de Blumenau. Integrante do Grupo de Pesquisa em Arte e Estética na Educação. Artista selecionado para a $1^{\text {a }}$ temporada de exposições do Museu de Arte de Blumenau de 2018. Atuação local nos principais segmentos: arte, educação e produção cultural.

Como citar esse artigo:

PERUZZO, Leomar; CARVALHO, Carla; GOTTARDI, Pedro. Dilatação corporal, performance art e a docência: um percurso de criação visual. Revista Digital do LAV, Santa Maria: UFSM, v. 11, n. 3, p. 47-66, set./dez. 2018. 